\title{
BIOMARCADORES NA RINITE ALÉRGICA: QUAL A IMPORTÂNCIA E POTENCIAL DIAGNOSTICO?
}

\section{Marcos Soares}

Mestre em Atenção Integral à Saúde pela (UNIJUI/ UNICRUZ), Brasil.

E-mail: marcossoaresorl@gmail.com

Gabriela Gomes Mânica

Especialista em Rinologia pelo HCPA/UFRGS, Brasil.

\section{Thiago Gomes Heck}

Doutor em Ciências do Movimento Humano pela UFRGS. Docente do PPGAIS-UNIJUI/UNICRUZ e das disciplinas de Fisiologia e Anatomia Humana da UNIJUI, Brasil.
RESUMO: O objetivo deste estudo é apontar quais os novos potenciais marcadores biológicos na rinite alérgica (RA). Buscou-se nas bases de dados Scielo e PUBMED artigos com os descritores "Rinite Alérgica" e "Biomarcadores" ou "Citocinas" ou "Interleucinas" ou "Eicosanoides", bem como na língua inglesa. A perspectiva do uso de novos biomarcadores na rinite alérgica vem sendo pesquisada, visto que marcadores sensíveis e específicos da doença poderiam permitir rápido diagnóstico, avaliação do estágio da doença e estimação da resposta ao tratamento. Vários métodos para coleta de amostras não invasivos ou semi-invasivos nas vias aéreas oferecem a possibilidade de mensuração de uma grande quantidade de novos biomarcadores na RA. Como potenciais biomarcadores, a análise do perfil de citocinas nasais apresenta uma boa caracterização diagnóstica (IL-5 e IL-13), além da relação de severidade da doença (IL-9 e IL-17B). Como avaliação isolada, a dosagem sérica de Proteína da Célula de Clara (CC16) parece ter grande potencial, pois permite o diagnóstico e seus níveis estão inversamente relacionados com a severidade da doença. Além disso, a dosagem de FeNO vem como uma arma importante para predizer asma nos pacientes com RA.

PALAVRAS-CHAVE: Biomarcadores; Rinite alérgica; Citocinas; Interleucinas; Eicosanoides.

\section{BIOMARKERS IN ALLERGIC RHINITIS: ITS IMPORTANCE AND DIAGNOSTIC POTENTIAL}

ABSTRACT: Current analysis deals with the new potential biological markers in allergic rhinitis. Scielo and PUBMED databases were researched for articles through descriptors "Allergic rhinitis" and "Biomarkers" or "Cytokines" or "Interleukins" or "Eicosanoids", in English and Portuguese. The use of new biomarkers for allergic rhinitis is researched since sensitive and specific markers provide a quick diagnosis, assessment of the disease's stage and estimates of treatment responses. Several invasive and semi-invasive methods for sample collection from the aerial pathways make possible the measurement of a great number of new biomarkers in allergic rhinitis. As potential biomarkers, the analysis of nasal cytokines offers a good diagnose (IL-5 and IL-13), coupled to the disease's severity (IL-9 and IL-17B). As an isolated evaluation, serum dosage of Clara Cell Protein (CC16) seems to be highly promising since it favors diagnosis with inversely related levels for the disease's severity. Further, FeNO dosage is an important tool to predict asthma in AR patients.

KEY WORDS: Biomarkers; Allergic rhinitis; Cytokines; Interleukines; Eicosanoids. 


\section{INTRODUÇÃO}

A rinite alérgica (RA) é diagnosticada com base na combinação da história de dois ou mais sintomas nasais (espirros, prurido, obstrução nasal e coriza) e confirmação da suspeição de sensibilização pelo teste de puntura ou testes imunoglobulina-E (IgE) específicos (HELLINGS et al., 2017). RA é uma das doenças mais comuns em adultos e a doença crônica mais comum em crianças nos Estados Unidos. É estimado que a RA afeta aproximadamente um em cada seis americanos e gera $2 \mathrm{a}$ 5 bilhões de dólares em gastos anualmente (SEIDMAN et al., 2015). O International Study of Asthma and Allergies in Childbood (ISAAC), um estudo mundial de alergias em crianças, encontrou ampla variação na prevalência de RA entre países, com taxa mais baixa de 1,5\% no Irã e mais alta de $39,7 \%$ na Nigéria. Sua prevalência varia com genética, epigenética e exposição ambiental em vias complexas que nós ainda não entendemos plenamente (SEIDMAN et al., 2015).

Pela alta prevalência, ela é um importante problema de saúde com grande impacto na vida social dos pacientes, performance escolar e produtividade no trabalho. Estudos epidemiológicos têm consistentemente mostrado que asma e rinite frequentemente coexistem nestes pacientes. A presença de rinite alérgica aumenta em $40 \%$ a probabilidade de asma e o tratamento da RA nestes pacientes está relacionado com maior controle da asma (WHEATLEY; TOGIAS, 2015).

A RA é causada por reações mediadas por IgE contra alérgenos inalados e envolvimento de inflamação mucosa regida pelos linfócitos T helper tipo 2 (Th2). Os alérgenos mais importantes são os pólens e fungos sazonais, bem como os perenes encontrados em casa, como ácaros da poeira, animais de estimação, baratas, ratos e mofo. A sensibilização dos alérgenos inalados começa durante o primeiro ano de vida e a sensibilização dos alérgenos de casa precede a sensibilização de pólen (WHEATLEY; TOGIAS, 2015).

Quando uma pessoa é exposta a alérgeno que é sensibilizada, a sua ligação ao IgE dos mastócitos da mucosa resulta em sintomas nasais em minutos, pela liberação de substâncias vasoativas como a histamina, prostaglandina D2, e cisteinil-leucotrienos (LTC4,LTD4 E LTE4) (WHEATLEY; TOGIAS, 2015).
O diagnóstico da RA é frequentemente feito clinicamente com base nos sintomas característicos e uma boa resposta a tratamentos empíricos com antihistamínicos ou glicocorticoide nasal. O diagnóstico formal é baseado na evidência da sensibilização, medido tanto pela presença de alérgeno específico para IgE no soro ou por testes alérgicos cutâneos positivos e história de sintomas que correspondem com a exposição ao alérgeno sensível (WHEATLEY; TOGIAS, 2015). O prurido é o sintoma mais sugestivo de etiologia alérgica e envolve não somente o nariz, mas também o palato, a garganta, os olhos e as orelhas (BAROODY; NACLERIO, 2010).

A perspectiva do uso de novos biomarcadores na prática clínica da RA vem sendo procurada por diversos pesquisadores. O objetivo deste estudo é apontar quais os novos potenciais marcadores biológicos na RA com sensibilidade e especificidade para permitir rápido diagnóstico, avaliação do estágio da doença e estimação da resposta ao tratamento.

Trata-se de um artigo de revisão de literatura onde foram consultadas as bases de dados Scielo e PUBMED em busca de artigos que possuam os descritores "Rinite Alérgica" e "Biomarcadores" ou "Citocinas" ou "Interleucinas" ou "Eicosanoides", bem como na língua inglesa. Foi dado prioridade aos artigos dos últimos dez anos, porém alguns artigos mais antigos foram selecionados por sua importância na discussão do tema.

\section{BIOMARCADORES DE DIAGNÓSTICO FORMAL DA RINITE ALÉRGICA}

Um biomarcador é um sinal físico ou medida laboratorial que pode servir como um indicador de um processo biológico ou como resposta a uma intervenção farmacológica. Idealmente, ele deve possuir relevância clínica, indicando clara relação entre eventos patofisiológicos na desordem, alta sensibilidade e especificidade, confiabilidade, reprodutibilidade, simplicidade na coleta de amostras e técnica de mensuração que promove a difusão do uso (DIAMANT et al., 2010). Biomarcadores podem ser empregados em vários propósitos, incluindo diagnóstico, graduação 
e monitoramento da atividade e progressão da doença ou monitorando preditores de resposta ao tratamento. Quando se implementam biomarcadores em ensaios clínicos ou monitorizações da rinite alérgica, é importante considerar a heterogeneidade da resposta inflamatória, a qual pode ter implicações na seleção de biomarcadores adequados (DIAMANT et al., 2010).

Os testes validados para confirmar o diagnóstico de RA são os cutâneos e o teste in vitro dos níveis séricos de anticorpos específicos para IgE (BAROODY; NACLERIO, 2010; HELLINGS et al., 2017). Testes cutâneos de hipersensibilidade imediata são amplamente usados para demonstrar uma reação alérgica mediada pelo IgE na pele. Estes testes representam grande ferramenta diagnóstica no campo da alergia. Se realizado adequadamente, eles rendem evidência confirmatória para um diagnóstico de alergia específica (BOUSQUET et al., 2008). O teste cutâneo recomendado é o teste de Puntura ou Prick Test que apresenta alto grau de correlação com os sintomas. Os testes intradérmicos podem induzir reações falso-positivas e são menos seguros porque podem desencadear reações sistêmicas (WHEATLEY; TOGIAS, 2015).

Para a realização do Prick Test, um instrumento afiado (agulha hipodérmica ou lanceta) é passado por meio de uma gota do extrato alergênico ou das soluções de controle (histamina, salina) em um ângulo de $45 \mathrm{a}$ 60 graus com a pele. Uma reação de pápula ou eritema, vista dentro de 15 minutos após puntura, ocorre se o paciente é sensível ao antígeno específico, que demonstra existência de anticorpos IgE específicos nos mastócitos intradérmicos (BAROODY; NACLERIO, 2010).

$\mathrm{O}$ teste cutâneo é rápido e barato, mas tem certas desvantagens como reatividade da pele pode ser afetada pela ingestão prévia de anti-histamínicos e outras drogas, crianças frequentemente não toleram múltiplas picadas de agulha, condições dermatológicas prévias ou coexistentes, como eczemas ou dermografismo, podem impedir a performance dos testes cutâneos, a potência do extrato deve ser mantida e reações sistêmicas podem acontecer, como a anafilaxia. Qualquer reação no controle negativo atrapalhará a interpretação do exame. Os controles positivos são muito importantes para detectar supressões por medicamentos ou doença e determinar variações na técnica (BAROODY; NACLERIO, 2010).

A IgE sérica total está elevada em 30 a 40\% dos pacientes com RA, mas pode estar elevada em paciente com condições não alérgicas e pessoas normais, tendo uso limitado no diagnóstico da RA. Por outro lado, a detecção de anticorpos IgE específicos no soro é útil no diagnóstico da RA, embora menos sensíveis do que os testes cutâneos. Estes testes eliminam a necessidade de múltiplas picadas na pele, mas são mais caros e mais demorados que os testes cutâneos. Porém, os níveis de IgE específica basal medida em crianças com RA sazonal durante a temporada do pólen, esteve associada à severidade dos sintomas, demonstrando valor prognóstico da doença (BAROODY; NACLERIO, 2010).

Por outro lado, muitas pessoas assintomáticas podem ter testes cutâneos ou sanguíneos positivos para IgE específica. Por este motivo, o diagnóstico é baseado na história clínica positiva para RA em associação a testes diagnósticos positivos. Portanto, um teste positivo, seja in vitro ou teste cutâneo, isolado, sem correlação clínica de alergia não confirma o diagnóstico de RA (BAROODY; NACLERIO, 2010).

\section{BIOMARCADORES EM INVESTIGAÇÃO NA RINITE ALÉRGICA}

Há dois tipos de biomarcadores sendo estudados na RA: os locais, com avaliação de frações celular, solúvel ou volátil, e sanguíneos, por avaliação celular ou substâncias solúveis. Na análise local, o lavado nasal (LN) tem a vantagem de permitir investigação citológica concomitante, por meio da análise do precipitado da centrifugação, mas desvantagem na diluição do fluido nasal, que pode tornar alguns mediadores indetectáveis pela técnica (RIECHELMANN et al., 2003). Assim, a avaliação da inflamação nasal por biomarcadores oferece uma leitura mais objetiva e direta que pode contribuir para o entendimento dos mecanismos da RA, monitorar a severidade da doença e avaliar os efeitos dos tratamentos. Porém, a maioria das técnicas e biomarcadores ainda aguarda validação (DIAMANT et al., 2010). 


\subsection{CITOCINAS}

As citocinas constituem um grupo diverso de moléculas imunomoduladoras e sinalizadoras com muitas funções na saúde e doença, tendo papel essencial na mediação da inflamação alérgica, principalmente as interleucinas (IL) (SCADDING, 2014).

As citocinas podem ser mensuradas por várias técnicas. Os níveis séricos de citocinas produzidas pela mucosa nasal são geralmente baixos, mas diferenças entre pacientes com RA e controles têm sido identificadas (SAKASHITA et al., 2008). Porém, a análise local por lavado, escovado ou biópsia é a mais estudada (KITAMURA et al., 2012).

Estudos do perfil das citocinas durante a exposição natural a alérgenos geram informação do estado da doença usual dos pacientes com RA, mas não no tempo imediato do curso da resposta alérgica. Níveis elevados de IL-4, IL-5 e IL-10, acompanhados de eosinófilos elevados, foram encontrados no lavado nasal de crianças escolares com rinite sazonal relacionada ao pólen (BENSON et al., 1997).

Dentro de minutos após exposição alergênica, as citocinas derivadas das células Th2 permanecem em níveis basais (SCADDING, 2014). Um aumento de IL-4, IL-5 e IL-13 pode ser detectado no fluido nasal a partir de 3-4 h, com pico de 6-9 h, voltando a níveis basais em 24 h. Há uma correlação positiva muito forte entre citocinas, particularmente IL-13 e IL-5 ( $\mathrm{r}=0.91, p<0,001)$, sendo que esta aparece em altas concentrações, com níveis maiores que $1000 \mathrm{pg} / \mathrm{mL}$. Por outro lado, as concentrações de IL-4 e IL-9 são baixas (IL-4: 0-200 pg/mL e IL-9: 0-100 $\mathrm{pg} / \mathrm{mL}$ ) (SCADDING et al., 2012). Em adultos jovens com RA, a exposição ao pólen aumentou significantemente os níveis nasais de eosinófilos, interleucina-5, IL-6, IL-13 e proteína inflamatória de macrófago-1 $\beta$, demonstrando que estes fatores podem ser usados como biomarcadores imunológicos para determinar eficácia de tratamentos antialérgicos (BADORREK et al., 2017). Além disso, em crianças, os níveis de IL-5 nasais estão aumentados após teste de provocação nasal por alérgeno em rinite alérgica local (ZICARI et al., 2016).

Um estudo comparou os mediadores de fluído nasal na RA sazonal e rinite viral. Alérgicos têm proteína catiônica eosinofílica (PCE), triptase e IL-5 elevadas, já a infecção viral produziu aumento de uma série de citocinas inflamatórias, incluindo IL-1 $\beta$, IL-6, IL-7, IL-17, IFN $\gamma$, IL-8, TNF $\alpha$ e GM-CSF, mas também de IL-4 e IL-5 (KLEMENS et al., 2007). Estes mediadores podem ter utilidade no diagnóstico diferencial da RA e rinite viral, já que muitos sintomas na fase aguda são semelhantes.

A IL-9, na mucosa nasal, estimula a infiltração tecidual pelos mastócitos e eosinófilos, sendo sobrerregulada na mucosa nasal durante a temporada da polinização (NOURI-ARIA et al., 2005). Além disso, seus níveis séricos têm relação significativa com a severidade dos sintomas, demonstrada por uma relação moderada positiva entre IL-9 e prurido nasal $(\mathrm{r}=0,563, p<0,001)$, espirros $(r=0,543, p<0,001)$, rinorreia $(r=0,706$, $p<0,001)$ e uma pobre correlação negativa com a severidade da obstrução nasal $(\mathrm{r}=-0.0371, p=0,02)$. Isto apoia o papel patogênico da IL-9 na indução da produção de muco, embora futuros estudos sejam necessários neste contexto. IL-9 sérica pode ser considerada um biomarcador substituto para RA aguda, que pode ser útil na avaliação destes pacientes (CIPRANDI, 2010).

Um estudo observou a expressão da IL-17A na biópsia nasal em três grupos: pacientes com rinite alérgica perene, rinite não alérgica eosinofílica e rinite não alérgica hipertrófica. $\mathrm{O}$ número de células positivas para IL-17A foi significantemente mais alta no grupo com RA perene quando comparado com rinite hipertrófica $(p=0.002)$ e rinite não alérgica eosinofílica $(p=0.021)$. Houve correlação positiva entre IL-17A e sintomas nasais $(\mathrm{r}=0.43, p=0.011)$ e com contagens de eosinófilos $(r=0.623, p<0.001)$. Estes dados associam a IL-17A com a patofisiologia da RA, incluindo severidade da doença e eosinofilia nasal, podendo servir como futuro biomarcador na RA (MAKIHARA et al., 2014).

Outro estudo, na avaliação de células mononucleares de sangue periféricos, evidenciou significante aumento da expressão de IL-22 e IL-17A quando comparados aos indivíduos saudáveis $(p=0.0004$ e $p=0.0001$, respectivamente), porém somente a IL22 se mostrou correlacionada com a severidade da RA $(p=0.0238)$, podendo ser um potencial biomarcador de severidade da doença. Dentre o grupo saudável, mas com testes positivos para IgE específica (assintomáticos, 
mas sensibilizados) houve aumento significativo da expressão de IL-22 e IL17A em comparação ao grupo saudável não sensibilizado (FARFARIELLO et al., 2011). Além disso, a expressão aumentada de IL-22 e IL-17A em pacientes assintomáticos sensibilizados pode contribuir para o entendimento dos mecanismos envolvidos no desenvolvimento precoce da doença alérgica, provendo então, novos possíveis alvos para intervenção terapêutica futura.

O aumento de outras citocinas como as eotaxina, RANTES, MCP-1 e MIP-1 $\alpha$ também tem sido identificado na RA(SCADDING, 2014). RANTES tem se mostrado elevado em casos de RA sazonal em relação à RA perene (KÖNIG et al., 2015).

Portanto, a avaliação do perfil de citocinas na secreção nasal pode ser importante para o diagnóstico, mas também como possibilidades de alvos terapêuticos no futuro (KÖNIG et al., 2015).

\subsection{EICOSANÓIDES}

O 8-isoprostano, prostaglandina E2 (PGE2) e cisteinil-leucotrienos (cis-LT), que constituem produtos finais do metabolismo do ácido aracdônico, podem ser detectáveis no lavado nasal coletado de pacientes com RAe podem servir como marcadores de inflamação na mucosa nasal (CIEBIADA; GÓRSKI; ANTCZAK, 2014). Na avaliação de pacientes com RA sazonal, as concentrações de cis-LT e 8-isoprostano no LN aumentaram significantemente no auge da estação do pólen ( $p<0,05$ para ambos) e os níveis de PGE2 diminuíram $(p<0,01)$, sendo que este teve uma correlação positiva com o número de eosinófilos nasais $(\mathrm{r}=0,67, p=0,039)$. Apesar da exposição ao pólen aumentar significantemente a média de escores nasais (3,04 para 5,65, $p<0,001)$, não foi encontrada correlação entre severidade de sintomas e as concentrações destes mediadores (CIEBIADA; GÓRSKI; ANTCZAK, 2014).

Os cis-LT também foram avaliados como biomarcadores em crianças com RA no condensado de ar expirado (CAE). Quando medido fora da exposição alergênica natural, pode discriminar entre indivíduos saudáveis e com RA, com sensibilidade de $87.8 \%$ e especificidade de $76.4 \%$, para o limite de $39.05 \mathrm{pg} /$ $\mathrm{mL}$. Além disso, quando analisado em conjunto com a diferença do pico de fluxo inspiratório nasal, medido antes e depois de provocação nasal alergênica, permite sensibilidade diagnóstica de quase $100 \%$ e especificidade aumentada para 84.6\% (ZAGÓRSKA et al., 2013). Porém, o teste de provocação nasal tem o inconveniente de provocar ou piorar os sintomas nasais do paciente, e deve ser cuidadosamente avaliado para o uso clínico.

Outro estudo mostrou altos níveis de leucotrieno B4 (LTB4) e 8-isoprostano em lavado nasal e altos níveis de LTB4 em CAE nos pacientes com RA $(p<0.0001$ para ambos). Houve também correlação do LTB4 do lavado nasal e CAE ( $r=0.313, p=0.048)$ (TANOU et al., 2009).

\section{3 ÓXIDO NÍTRICO EXALADO (FeNO) E NASAL (nNO)}

O óxido nítrico está presente em altas concentrações nas vias aéreas superiores e é considerado um biomarcador com efeitos benéficos, pela inibição de vírus e bactérias e estimulação da motilidade ciliar (LUNDBERG, 2008). Em contraste, condições com baixa produção de nNO, incluindo a fibrose cística e discinesia ciliar primária, são associadas a alta suscetibilidade de infecções sinusais. Inflamação alérgica induz altos níveis de $\mathrm{NO}$ e muitos estudos mostram níveis aumentados em paciente sintomáticos e assintomáticos com RA, quando comparados aos controles não alérgicos. Níveis normais de nNO estão entre 400-900 ppb (DIAMANT et al., 2010; LUNDBERG, 2008).

A medida do FeNO, em paciente com rinite e sem asma, foi relatada como variável independente como preditora para o desenvolvimento de asma. Após cinco anos, $20 \%$ das crianças estudadas desenvolveram asma, todas pertencentes ao grupo com FeNO elevada $(>35$ p.p.b.), predizendo significantemente 0 início de asma (OR:2.49, $p<0,01)$. Portanto, valores acima de 35p.p.b., considerados patológicos, podem predizer com confiabilidade futuro início de asma em crianças com RA (DI CARA et al., 2014; SHAKER, 2014). Outros estudos também mostram a relevância do FeNO como possível marcador preditivo para hiperresponsividade brônquica em paciente com RA, sugerindo valores patológicos acima de $50 \mathrm{ppb}$, demonstrando a íntima relação entre as vias aéreas alta e baixa, sugerindo que sua medida poderia ser uma ferramenta de triagem na identificação de sujeitos 
com RA para o risco de desenvolver asma (CIPRANDI et al., 2017; CIRILLO et al., 2013).

\subsection{PROTEÍNA DAS CÉLULAS DE CLARA}

A proteína das células de Clara (CCSP ou CC16), uma pequena proteína secretada nas vias aéreas principalmente pelas células de Clara, tem relação com asma e rinite em particular porque seu gene é localizado na região p12-q13 do cromossoma humano 11 que é envolvido com regulação da inflamação. Ela está diminuída na asma e na inflamação do trato respiratório tanto em homens como em animais. A CC16 é um biomarcador de alto interesse nas doenças das vias aéreas e pode difundir passivamente do trato respiratório para o sangue, sendo inclusive excretada pelo trato urinário. CC16 está atribuída a um papel protetor contra o estresse oxidativo e inflamação do trato respiratório (IRANDER et al., 2012).

Em crianças, tanto a CC16 sérica e no lavado nasal tiveram significante correlação negativa com o escore de sinais e sintomas nasais e contagem de eosinófilos. Na avaliação diagnóstica da RA, a CC16 sérica foi significantemente diminuída entre o grupo com RA quando comparada com controles saudáveis $(p<0.05$, $2.03 \pm 0.59 \mu \mathrm{g} / \mathrm{L}$ vs. $8.38 \pm 4.87 \mu \mathrm{g} / \mathrm{L}$ ), demonstrando o melhor valor de corte em $3.75 \mu \mathrm{g} / \mathrm{L}$ com uma sensibilidade de $100 \%$, especificidade de $80 \%$, com uma acurácia diagnóstica de $90 \%$, enquanto no lavado nasal não teve relação. Portanto, baixos níveis séricos de CC16 podem ser preditores de RA e são inversamente correlacionados com a severidade da doença (DERAZ et al., 2012).

\subsection{OUTROS BIOMARCADORES}

Moléculas de adesão são críticas na patogênese da RA que contribuem para persistência do recrutamento celular e inflamação. Um estudo avaliou a relação entre a severidade das doenças das vias aéreas e a concentração sérica da molécula de adesão intercelular 1 (ICAM-1) e TNF- $\alpha$, além da expressão nasal de ICAM-1 por meio de biópsia nasal. Em todos os pacientes com RA, o ICAM1 sérico e expressão de ICAM-1 nasal tiveram correlação positiva com a severidade da doença. O TNF- $\alpha$ diferiu significantemente entre pacientes com RA e asma (1.065 vs. $3.46 \mathrm{pg} / \mathrm{mL}$, respectivamente). Em asmáticos, a TNF- $\alpha$ não foi capaz de diferenciar severidade de doença (GORSKA-CIEBIADA et al., 2006).

A expressão de moléculas de adesão vascular 1 (VCAM-1) foi encontrada significantemente sobrerregulada em biópsia nasal de paciente alérgicos 24 horas após provocação por antígeno concomitantemente com aumento significativo do número de eosinófilos. Estes estudos com moléculas de adesão in vivo sugerem que estas moléculas têm papel importante no recrutamento celular dos sítios inflamatórios (BAROODY; NACLERIO, 2010).

$\mathrm{Na}$ avaliação de pacientes em relação à resposta ao tratamento clínico da RA com glicocorticoides nasais, a análise proteômica de lavado nasal com espectrometria de massa e análise multivariada, identificou uma combinação de proteínas que melhor separam indivíduos que tenham alta ou baixa resposta ao tratamento com glicocorticoides. Foi demonstrado que a orosomucoide (ORM) $(p<0.01)$, cadeia alfa do fibrinogênio (FGA) $(p<0.05)$ e apolipoproteína H (APOH) $(p<0.01)$, estavam elevadas nos respondedores ruins, antes e depois do tratamento. Dessa forma, a análise desta combinação de proteínas demonstra relação de resistência ao tratamento com glicocorticoides na RA (WANG et al., 2011).

A dosagem sérica da lactoferrina se mostra promissora no diagnóstico de RA sensíveis a ácaro, mesmo em períodos sem sintomas. Para fins diagnósticos, níveis menores que $307 \mathrm{ng} / \mathrm{mL}$, avaliados por curva ROC, demonstram sensibilidade de $81.4 \%$ e especificidade de $58 \%$. Quando combinada com os níveis séricos de IgE específica para ácaro, a sensibilidade e especificidade foram de 76.7 e $79.2 \%$, respectivamente, para predizer RA (CHOI et al., 2010). Portanto, a lactoferrina sérica está relacionada com a RA sensível ao ácaro, e em combinação com os níveis de IgE específica para ácaro, pode ser um potencial biomarcador para detecção precoce da RA.

Outros possíveis biomacardores são os microRNAs (miRNAs). Eles são moléculas pequenas (20-25 nucleotídeos), com uma camada, sendo RNAs não codificados que pós-transcricionalmente regulam a expressão gênica por meio de interações com RNA mensageiro (mRNA). Estão emergindo como moléculas 
regulatórias importantes que podem estar envolvidas na patogênese de várias doenças e podem ser biomarcadores não invasivos para diagnosticar e caracterizar asma e rinite alérgica. Os miRNAs atuam como importante papel na regulação de citocinas (PANGANIBAN et al., 2016).

A expressão plasmática de miRNA, mensurada por PCR tempo real quantitativo, identificou 30 miRNAs que foram diferentemente expressos entre saudáveis, alérgicos e asmáticos, tendo alto potencial para diagnóstico de RA e asma. Os miRNAs - miR-125b, miR-16, miR-299-5p, miR-126, miR-206 e miR-133b - se mostraram unicamente expressos em paciente com RA e asma e têm potencial para uso para diagnóstico e caracterização destas doenças (PANGANIBAN et al., 2016).

\section{CONSIDERAÇÕES FINAIS}

Vários métodos para coleta de amostras não invasivas ou semi-invasivas nas vias aéreas oferecem a possibilidade de mensuração de uma grande quantidade de biomarcadores na RA. Em especial, a análise do perfil de citocinas nasais apresenta boa caracterização diagnóstica (IL-5 e IL-13), além da relação de severidade da doença (IL-9 e IL-17B). Como avaliação isolada, a dosagem sérica de CC16 parece ter grande potencial, pois permite o diagnóstico de RA e seus níveis estão inversamente relacionados com a severidade da doença. Além disso, a dosagem de FeNO vem como uma arma importante para predizer asma nos pacientes com RA. Portanto, estes biomarcadores podem ser ferramentas úteis para a prática clínica em um futuro próximo.

\section{REFERÊNCIAS}

BADORREK, P. et al. Specificity and reproducibility of nasal biomarkers in patients with allergic rhinitis after allergen challenge chamber exposure. Ann Allergy Asthma Immunol, v. 118, n. 3, p. 290-297, 2017.

BAROODY, F. M.; NACLERIO, R. M. Immunology of the Upper Airway and Pathophysiology and Treatment of Allergic Rhinitis. In: RICHARDSON, M. A. et al. (Ed.). . Cummings otolaryngology head and neck surgery.
Fifth Edit ed. [s.1.]: Mosby, 2010. p. 597-623.

BENSON, M. et al. Cytokines in nasal fluids from school children with seasonal allergic rhinitis. Pediatr Allergy Immunol, v. 8, n. 3, p. 143-149, 1997.

BOUSQUET, J. et al. Allergic Rhinitis and its Impact on Asthma ( ARIA ) 2008 Update. Allergy, v. 63, n. suppl. 86, p. 8-160, 2008.

CHOI, G. S. et al. Serum lactoferrin level as a serologic biomarker for allergic rhinitis. Clin $\operatorname{Exp}$ Allergy., v. 40, n. 3, p. 403-410, 2010.

CIEBIADA, M.; GÓRSKI, P.; ANTCZAK, A. Evaluation of eicosanoids in nasal lavage as biomarkers of inflammation in patients with allergic rhinitis. Arch Med Sci., v. 10, n. 6, p. 1123-1128, 2014.

CIPRANDI, G. Serum interleukin 9 in allergic rhinitis. Ann Allergy Asthma Immunol, v. 104, n. 2, p. 180-181, 2010.

CIPRANDI, G. et al. Fractional Exhaled Nitric Oxide: A Potential Biomarker in Allergic Rhinitis? Int Arch Allergy Immunol., v. 172, n. 2, p. 99-105, 2017.

CIRILLO, I. et al. Exhaled nitric oxide may predict bronchial hyperreactivity in patients with allergic rhinitis. Int Arch Allergy Immunol., v. 160, n. 3, p. 322-328, 2013.

DERAZ, T. E. et al. Serum and nasal lavage fluid Clara cell protein decreases in children with allergic rhinitis. Int $\mathbf{J}$ Pediatr Otorhinolaryngol., v. 76, n. 9, p. 1241-1244, 2012.

DI CARA, G. et al. Exhaled nitric oxide in children with allergic rhinitis: a potential biomarker of asthma development. Pediatr Allergy Immunol., v. 26, n. 1, p. 85-87, 2014.

DIAMANT, Z. et al. Biomarkers in asthma and allergic rhinitis. Pulm Pharmacol Ther., v. 23, n. 6, p. 468-481, 2010.

FARFARIELLO, V. et al. IL-22 mRNA in peripheral blood 
mononuclear cells from allergic rhinitic and asthmatic pediatric patients. Pediatr Allergy Immunol., v. 22, n. 4, p. 419-423, 2011.

GORSKA-CIEBIADA, M. et al. Intercellular adhesion molecule 1 and tumor necrosis factor alpha in asthma and persistent allergic rhinitis: relationship with disease severity. Ann Allergy Asthma Immunol, v. 97, n. 1, p. 66-72, 2006.

HELLINGS, P. W. et al. Positioning the Principles of Precision Medicine in Care Pathways for Allergic Rhinitis and Chronic Rhinosinusitis - an EUFOREA-ARIA-EPOSAIRWAYS ICP statement. Allergy, 17 mar. 2017.

IRANDER, K. et al. Clara cell protein in nasal lavage fluid and nasal nitric oxide: biomarkers with anti-inflammatory properties in allergic rhinitisClinical and Molecular Allergy. BioMed Central, 2012. Disponível em: <http:// www.clinicalmolecularallergy.com/content/10/1/4>. Acesso em: 17 abr. 2016.

KITAMURA, Y. et al. Preseasonal prophylactic treatment with antihistamines suppresses IL-5 but not IL-33 mRNA expression in the nasal mucosa of patients with seasonal allergic rhinitis caused by Japanese cedar pollen. Acta Otolaryngol., v. 132, n. 4, p. 434-8, abr. 2012.

KLEMENS, C. et al. Mediators and cytokines in allergic and viral-triggered rhinitis. Allergy Asthma Proc., v. 28, n. 4, p. 434-41, jan. 2007.

KÖNIG, K. et al. Cytokine profiles in nasal fluid of patients with seasonal or persistent allergic rhinitis. Allergy Asthma Clin Immunol., v. 11, n. 1, p. 26, 22 dez. 2015.

LUNDBERG, J. O. Nitric oxide and the paranasal sinuses. Anat Rec (Hoboken)., v. 291, n. 11, p. 1479-1484, 2008.

MAKIHARA, S. et al. Local expression of interleukin-17a is correlated with nasal eosinophilia and clinical severity in allergic rhinitis. Allerg y Rhinol (Providence), v. 5, n. 1, p. 22-27, 2014.

NOURI-ARIA, K. T. et al. IL-9 and c-Kit+ mast cells in allergic rhinitis during seasonal allergen exposure: effect of immunotherapy. J Allerg y Clin Immunol., v. 116, n.
1, p. 73-9, jul. 2005.

PANGANIBAN, R. P. et al. Circulating microRNAs as biomarkers in patients with allergic rhinitis and asthma. J Allerg y Clin Immunol., v. 137, n. 5, p. 1423-1432, 2016.

RIECHELMANN, H. et al. Biological markers in nasal secretions. Eur Respir J., v. 21, n. 4, p. 600-605, 2003.

SAKASHITA, M. et al. Association of serum interleukin-33 level and the interleukin-33 genetic variant with Japanese cedar pollinosis. Clin Exp Allerg y., v. 38, n. 12, p. 187581, dez. 2008.

SCADDING, G. Cytokine profiles in allergic rhinitis. Curr Allergy Asthma Rep. , v. 14, n. 5, p. 435, 2014.

SCADDING, G. W. et al. Optimisation of grass pollen nasal allergen challenge for assessment of clinical and immunological outcomes. J Immunol Methods., v. 384, n. 1-2, p. 25-32, 2012.

SEIDMAN, M. D. et al. Clinical Practice Guideline: Allergic Rhinitis. Otolaryngol Head Neck Surg., v. 152, n. 1 Suppl, p. S1-S43, 2015.

SHAKER, M. New insights into the allergic march. Curr Opin Pediatr., v. 26, n. 4, p. 516-20, ago. 2014.

TANOU, K. et al. Inflammatory and oxidative stress biomarkers in allergic rhinitis: the effect of smoking. Clin Exp Allerg y. , v. 39, n. 3, p. 345-353, 2009.

WANG, $\mathrm{H}$. et al. Identification of novel biomarkers in seasonal allergic rhinitis by combining proteomic, multivariate and pathway analysis. PLoS ONE, v. 6, n. 8, 2011.

WHEATLEY, L. M.; TOGIAS, A. Clinical practice: allergic rhinitis. N Engl J Med., v. 372, n. 5, p. 456-463, 29 jan. 2015.

ZAGÓRSKA, W. et al. Increased cys-leukotrienes in exhaled breath condensate and decrease of PNIF after intranasal allergen challenge support the recognition of allergic rhinitis in children. Arch Immunol Ther Exp 
(Warsz)., v. 61, n. 4, p. 327-332, 2013.

ZICARI, A. M. et al. Local allergic rhinitis in children: Novel diagnostic features and potential biomarkers. Am J

Rhinol Allergy., v. 30, n. 5, p. 329-334, 2016.

Recebido em:10 de agosto de 2016 Aceito em: 31 de maio de 2017 